\title{
Analisa Karakteristik Katup Ekspansi Termostatik Dan Pipa Kapiler Pada Sistem Pendingin Water Chiller
}

\author{
Alimansyah Fazri ${ }^{1}$, Budha Maryanti ${ }^{2}$ \\ ${ }^{1,2)}$ Program Studi Teknik Mesin Fakultas Teknologi Industri Universitas Balikpapan \\ Jl. Pupuk Raya Balikpapan. Telp./Fax. 0542-764205 \\ Email : afmbsmw@yahoo.com; budha_maryanti@yahoo.com
}

\begin{abstract}
The cooler system of chiller water consists of two cycles which interconnected each other that is the primary cycle and the secondary cycle. This primary cycle is the cooler system of vapor compression and the secondary cycle is the water cooling system which is circulated and met the part of evaporator from primary system. This research is conducted to compare the value of COP (Coefficient Of Performance) by used two expansion devices that is thermostatic expansion valve $(T X V)$ and capillary pipe which are attached in primary cycle for unit of water chiller. The result of test of performance indicates that cooler system of water chiller when operating with TXV has the value of COP equal 3.86 to 4.01, while with capillary pipe equal 3.59 to 3.74 . The usage of TXV is capable to cool the evaporator output water (water chilled) to $10^{\circ} \mathrm{C}$, while at capillary pipe equal $12{ }^{\circ} \mathrm{C}$. Thereby the application of TXV if it is used to the cooler system of water chiller having performance is better to be compared by using the capillary pipe.
\end{abstract}

Key words: water chiller, The application of expansion device, COP (Coefficient Of Performance).

\begin{abstract}
Abstrak
Sistem pendingin water chiller terdiri dari dua siklus yang saling berkaitan yaitu siklus primer dan siklus sekunder. Pada siklus primer merupakan sistem pendingin kompresi uap dan pada siklus sekunder merupakan sistem pendinginan air yang disirkulasikan dan bertemu pada bagian evaporator dari sistem primer. Penelitian ini dilakukan untuk membandingkan nilai COP (Coefficient Of Performance) dengan menggunaan dua alat ekspansi yaitu katup ekspansi termostatik (TXV) dan pipa kapiler yang dipasang pada siklus primer pada unit water chiller. Hasil uji performansi menunjukkan bahwa sistem pendingin water chiller ketika beroperasi dengan TXV mempunyai nilai COP sebesar 3,86 hingga 4,01, sedangkan dengan pipa kapiler sebesar 3,59 hingga 3,74. Penggunaan TXV mampu mendinginkan air keluaran evaporator (chilled water) hingga $10^{\circ} \mathrm{C}$, sedangkan pada pipa kapiler sebesar $12^{\circ} \mathrm{C}$. Dengan demikian aplikasi TXV jika digunakan pada sistem pendingin water chiller mempunyai performansi yang lebih baik dibandingkan dengan menggunakan pipa kapiler.
\end{abstract}

Kata kunci : water chiller, aplikasi alat ekspansi, COP (Coefficient Of Performance).

\section{Pendahuluan}

Pada zaman modern saat ini bangunan gedung-gedung bertingkat dan perkantoran umumnya menggunakan sistem pengkondisi udara sentral. Hal ini karena pertimbangan biaya operasional serta perawatan lebih murah dan mudah. Salah satu sistem pengkondisi udara sentral yang digunakan adalah sistem water chiller. Untuk mendapatkan pendinginan yang diinginkan dari sistem water chiller ini, maka bagian evaporator dari sistem primer dibuat atau dirancangkan sedemikian rupa sehingga mampu menyerap kalor dari air (chilled water) yang akan didinginkan semaksimal mungkin sesuai dengan kapasitas dan kebutuhan.

Salah satu upaya yang dapat dilakukan dengan memasang alat ekspansi yang tepat dan sesuai dengan karakteristik sistem pendinginan water chiller tersebut. untuk

Adapun tujuan penelitian ini yaitu

Mengetahui besarnya nilai $C O P$ (Coefficient of Performance) yang dihasilkan oleh katup ekspansi 
1) termostatik atau Termostatic Expantion Valve (TXV) dan pipa kapiler.

2) Mengetahui perbandingan karakteristik efek pendingin yang dihasilkan ketika water chiller beroperasi menggunakan TXV dan pipa kapiler.

\section{Tinjauan Pustaka}

\subsection{Sistem Pendingin Water Chiller}

Pengkondisian udara adalah proses penanganan udara untuk mengontrol secara serempak terhadap temperatur, kelembaban, kebersihan dan distribusi untuk mencapai kondisi yang diinginkan. Dengan melakukan pengkondisian udara tersebut, setiap orang dapat mengatur temperatur, kelembaban udara sesuai dengan yang diinginkan sehingga dapat menghasilkan pengkondisian udara yang nyaman (comfortair conditioning). Di masyarakat alat pengkondisian udara ini biasa dikenal dengan sebutan AC (Air Conditioner), yang mana salah satu jenisnya adalah water chiller.

$A C$ jenis water chiller terdiri dari dua siklus yang saling berkaitan, siklus refrigeran primer dan refrigeran sekunder. Pada siklus primer refrigeran primer tersirkulasi melalui empat komponen utama $A C$ yaitu kompresor, kondensor, alat ekspansi, dan evaporator. Refrigeran dikompresikan oleh kompresor menuju kondensor kemudian menuju alat ekspansi dan evaporator. Prinsip kerja pada siklus primer ini merupakan prinsip kerja kompresi uap. Refrigeran primer mengalami evaporasi dengan menyerap panas dari refrigeran sekunder. Refrigeran sekunder yang biasa digunakan dalam hal ini adalah air utility (utility water). Pada sistem water chiller ini, air utility pertama kali didinginkan di ruang evaporator pada sistem refrigerasi untuk mendapatkan temperatur $8^{\circ} \mathrm{C}$ hingga $10^{\circ} \mathrm{C}$. Air utility (chilled water) yang sudah dingin ini kemudian dipompakan ke unit penanganan udara atau $A H U$ (Air Handling Unit) dan selanjutnya menuju terminal $F C U$ (Fan Coil Unit) dimana udara akan dikondisikan. Setelah melewati unit penanganan udara $A H U$ temperatur chilled water meningkat berkisar $16^{\circ} \mathrm{C}$ hingga $20^{\circ} \mathrm{C}$ dan dengan temperatur sebesar itu udara pada ruangan yang akan didinginkan dapat mencapai berkisar antara $18^{\circ} \mathrm{C}$ hingga $22^{\circ} \mathrm{C}$. Berikut adalah skema umum sistem pendingin water chiller :

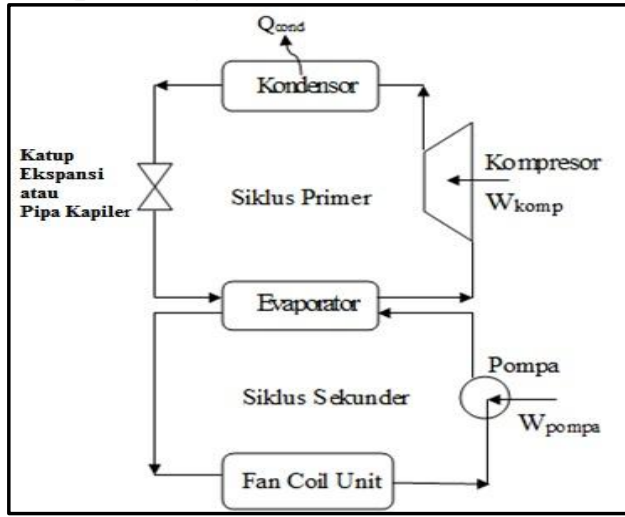

Gambar 1. Skema umum sistem pendingin water chiller

\subsection{Alat Ekspansi}

1. Katup ekspansi termostatik

Katup ekspansi termostatik adalah jenis katup yang paling banyak digunakan, karena efisiensinya tinggi dan mudah diadaptasikan dengan berbagai aplikasi refrigerasi. Bagian utama katup ekspansi termostatik adalah katup jarum dan dudukannya, diafragma, remote bulb yang berisi refrigeran cair, dilengkapi dengan pipa kapiler yang langsung terhubung ke diafragma, dan pegas yang dapat diatur tekanannya melalui sekrup pengatur tekanan. Seperti semua piranti kontrol laju aliran refigeran lainnya, katup ekspansi termostatik juga dilengkapi dengan filter dari kasa baja yang diletakkan di sisi masukan katup. Berikut gambar bagian dalam dari katup ekspansi termostatik :

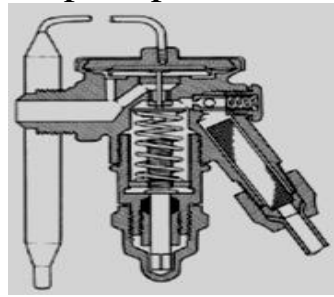

Gambar 2. Katup ekspansi termostatik (TXV) 
Remote bulb dipasang pada sisi keluaran evaporator, dicekam atau diklem kuat pada saluran outlet evaporator agar dapat mendeteksi atau merespon langsung temperatur refrigeran yang mengalir pada sisi outlet evaporator. Kerja katup ekspansi termostatik merupakan hasil interaksi tiga jenis tekanan yang bekerja pada diafragma, yaitu tekanan pegas dan tekanan evaporasi yang akan menekan diafragma sehingga cenderung menutup katup. Dan tekanan yang dihasilkan oleh refrigeran saturasi yang ada di dalam remote bulb bila refrigerannya mengembang yang melawan tekanan pegas dan tekanan evaporasi, sehingga cenderung membuka katup. Gambar berikut memperlihatkan skematis cara kerja TXV.

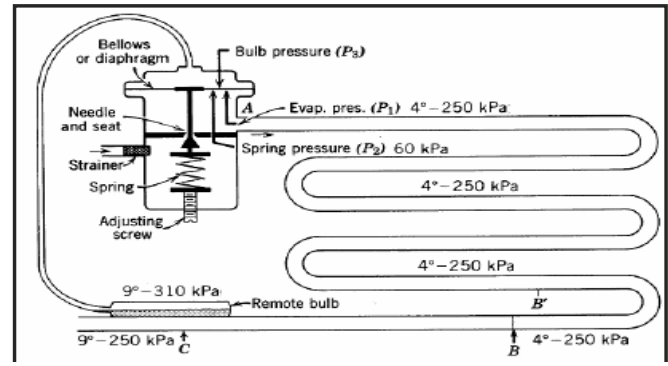

Gambar 3. Skematis cara kerja katup ekspansi termostatik

\section{Pipa Kapiler}

Sistem pengontrol laju refrigeran yang lebih sederhana adalah pipa kapiler. Seperti namanya pipa kapiler terdiri dari pipa panjang dengan diameter yang sangat kecil. Diameter pipa kapiler antara 0,25 inci sampai 0,375 inci. Pipa kapiler digunakan untuk menurunkan tekanan refrigeran dari kondisi sub-dingin hingga fasa campuran. Penurunan tekanan di dalam pipa kapiler disebabkan oleh gesekan dan percepatan refrigeran yang mengalir dalam pipa kapiler tersebut. Pipa kapiler biasanya digunakan untuk sistem yang berkapasitas kecil hingga $10 \mathrm{~kW}$.

Pada ukuran panjang dan diameter tertentu, pipa kapiler memiliki tahanan gesek yang cukup tinggi sehingga dapat menurunkan tekanan kondensasi yang tinggi ke tekanan evaporasi yang rendah.
Pipa kapiler berfungsi menakar jumlah refrigeran cair ke evaporator dan untuk menjaga beda tekanan antara tekanan kondensasi dan tekanan evaporasi agar tetap konstan.

\section{Metodologi Penelitian}

\subsection{Waktu dan Tempat Penelitian}

Penelitian ini dilakukan di salah satu Maintenance Workshop yaitu SPS/MNP/ELC Utility Workshop milik perusahaan Total E\&P Indonesie yang bergerak dibidang ekplorasi dan produksi minyak dan gas alam, sebagai Kontraktor Production Sharing (KPS) dengan Pertamina Direktorat Manajemen Production Sharing yang dibawah pengawasan oleh SKK Migas. SPS/MNP/ELC Utility Workshop ini berdiri sejak tahun 1977 dan beralamatkan di SPS (Senipah - Peciko-South Mahakam) Complex, Jalan Besar Handil Balikpapan, Sigagu, Kabupaten Kutai Kartanegara Kalimantan Timur. Penelitian ini dilakukan pada bulan Mei s/d Nopember 2015.

\subsection{Obyek Penelitian}

Adapun obyek penelitian yang diamati oleh Penulis adalah sebuah mesin pendingin York Water Chiller berdaya 2 PK, yang biasa digunakan mendinginkan ruang penyimpanan (store house) paralatan listrik dan instrumentasi di SPS.

\subsection{Alat dan Bahan Penelitian}

Seperti yang telah dijelaskan sebelumnya bahwa sistem pendinginan water chiller menggunakan dua siklus refrigerasi, yaitu siklus refrigeran primer dan siklus refrigeran sekunder, dan alat yang digunakan pada kedua siklus tersebut ialah berbeda. Berikut alat dan bahan yang terdapat didua siklus tersebut: 


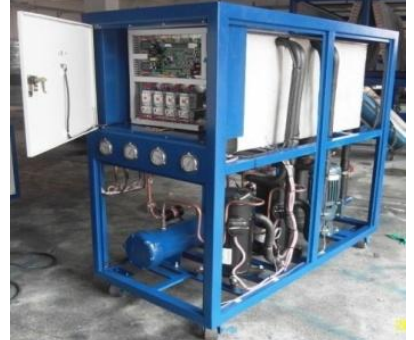

Gambar 4. Alat pengujian water chiller

Alat dan bahan yang terdapat pada siklus refrigeran primer antara lain :

1. Satu unit kompresor dengan daya $=2$ PK,

2. Satu unit kondensor dilengkapi dengan saluran udara,

3. Refrigeran jenis R-134a yang sudah ada dalam sistem,

4. Dua unit alat ekspansi berupa pipa kapiler dan katup ekspansi termostatik,

5. Dua buah katup di pasang pada sebelum masing-masing alat ekspansi,

6. Satu unit evaporator.

Alat dan bahan yang terdapat pada siklus refrigeran sekunder antara lain :

1. Satu unit pompa sentrifugal beserta katup yang terpasang pada discharge,

2. Satu unit penampungan air (utility water),

3. Satu unit meteran air untuk mengukur debit air.

Selain alat dan bahan di atas untuk penelitian ini juga memerlukan alat-alat instrumentasi tambahan diantaranya:

1. Thermometer digital dengan sensor termokopel dengan range $0^{\circ} \mathrm{C}$ hingga $150^{\circ} \mathrm{C}$, untuk mengukur temperatur refrigeran primer di titik tingkat keadaan 1, 2, 3, dan 4 (lihat gambar 2.1, halaman 5) dan juga untuk mengukur temperatur air utility yang keluar dan masuk dari chiller.

2. Amperemeter untuk mengukur besarnya arus listrik.

3. Voltmeter untuk mengukur tegangan listrik. Dengan diketahui arus dan tegangan listrik, kita dapat menghitung daya kompresor pada saat penelitian ini dilakukan.

4. Pressure Gauge $(P G)$ yang digunakan untuk pengukuran tekanan, untuk mendapatkan keadaan tekanan refrigeran digunakan pengukur tekanan tabung Bourdon yang banyak digunakan dalam pengukuran tekanan statik.

Sistem pemipaan juga mempunyai pengaruh yang besar terhadap kinerja dan efisiensi pada suatu sistem mesin pendingin water chiller ini. Sistem pemipaan merupakan saluran untuk mengalirkan refrigeran ke masing-masing komponen utama dengan bentuk siklus tertutup. Sistem pemipaan dibuat sedemikian rupa sehingga tidak terjadi kebocoran refrigeran yang merupakan sebagai fluida pendingin. Sistem pemipaan terbuat dari pipa tembaga dengan diameter $1 / 2$ inci untuk saluran dari evaporator ke kompresor, serta 3/8 inci dari kompresor ke kondensor. Dari kondensor ke alat ekspansi serta dari alat ekspansi ke evaporator menggunakan pipa tembaga dengan diameter $1 / 2$ inci. Skema sistem pemipaan dari sistem pendinginan ini dapat dilihat pada gambar berikut :

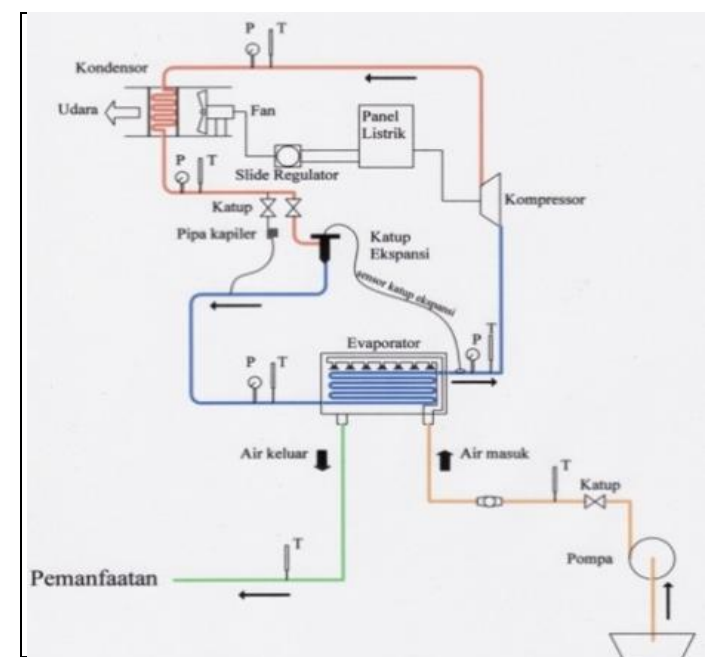

Gambar 5 Skema aliran sistem pendingin water chiller

\subsection{Prosedur Penelitian}

1. Melakukan uji performansi sistem kerja water chiller,

2. Pengamatan masing-masing alat ekspansi terhadap suatu debit air

a. Pada temperatur air keluar sistem water chiller, 
b. Pada temperatur refrigeran di siklus primer,

c. Dan juga pada penyerapan kalor di evaporator.

3. Melakukan perhitungan nilai COP (Coefficient Of Performance) pada kondisi aktual untuk katup ekspansi termostatik,

4. Melakukan perhitungan nilai $C O P$ (Coefficient Of Performance) pada kondisi aktual untuk pipa kapiler,

5. Melakukan perbandingan nilai $C O P$ (Coefficient Of Performance) aktual dari masing-masing alat ekspansi terhadap suatu debit air yang dialirkan,

\subsection{Diagram Alir Penelitian}

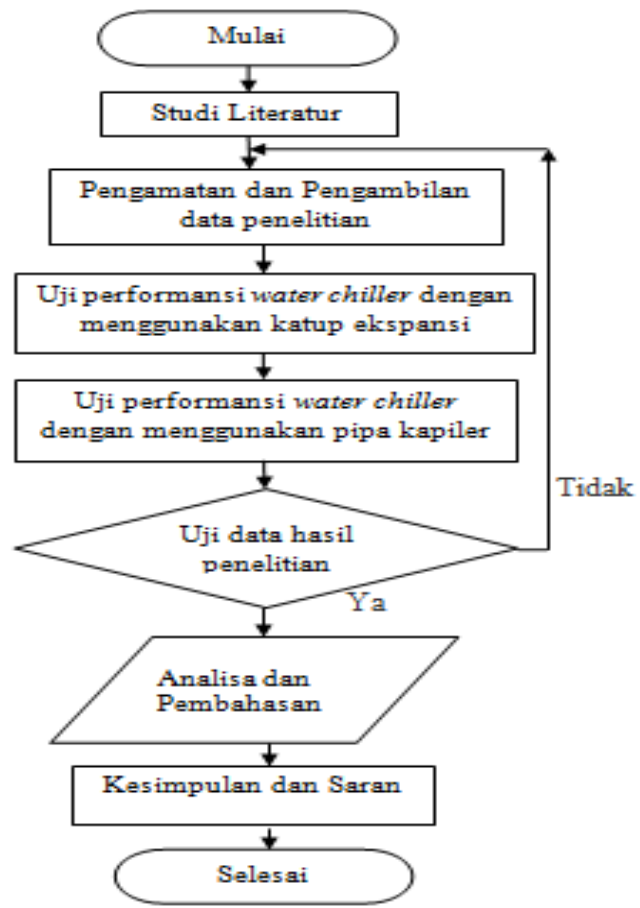

Gambar 6. Diagram Alir Penelitian

\subsection{Variabel Penelitian:}

a. Variabel Bebas

Pada penelitian ini variabel bebas terdiri dari :

- Jenis alat ekspansi (Katup Ekspansi Termostatik dan Pipa Kapiler berukuran $1 / 4$ inci).

- Debit air ( $\mathrm{m}^{3} /$ detik)

\section{b. Variabel Terikat}

1. Nilai koefisien performansi $(C O P)$

2. Temperature air keluar water chiller $\left({ }^{\circ} \mathrm{C}\right)$

\section{c. Variabel Kontrol}

- Jenis refrigeran R-134a.

\section{Hasil Dan Pembahasan}

\subsection{Data Penelitian}

Setelah melakukan serangkaian uji coba pada water chiller di SPS Utility Workshop, dimana pengujian masingmasing alat ekpansi pada water chiller yang beroperasi dilakukan secara bergantian. Pengujian ini mencakup pengambilan data diantaranya debit air yang dihasilkan oleh pompa, temperatur refrigeran yang keluar dari evaporator, temperatur air yang keluar dari evaporator, temperatur refrigeran keluaran kompresor, dan hasil perhitungan nilai $C O P$. Untuk menghitung seberapa besar nilai $C O P$ yang dihasilkan oleh water chiller baik ketika water chiller beroperasi menggunakan TXV maupun pada saat menggunakan pipa kapiler, pada penelitian ini menggunakan tabel temperatur refrigeran R-134a yang tersedia pada properties. Dimana besarnya nilai entalpi tersebut berdasarkan nilai temperatur yang didapat pada masing-masing kondisi debit air dan kemudian nilai-nilai entalpi tersebut kita masukkan kedalam persamaan.

Data penelitian ketika water chiller beroperasi dengan menggunakan TXV:

1) $\mathrm{Q} 1$ (debit air) $=0,000109 \mathrm{~m}^{3} /$ detik

$\mathrm{T} 1=14{ }^{\circ} \mathrm{C} \rightarrow h g 1=258,370 \mathrm{~kJ} / \mathrm{kg}$

$\mathrm{T} 2=66{ }^{\circ} \mathrm{C} \rightarrow h g 2=292,505 \mathrm{~kJ} / \mathrm{kg}$

$\mathrm{T} 3=52{ }^{\circ} \mathrm{C} \rightarrow h l 3 \approx h l 4=126,590 \mathrm{~kJ} / \mathrm{kg}$

$C O P=\frac{258,370-126,590}{292,505-258,370}=\frac{131,780 \mathrm{~kJ} / \mathrm{kg}}{34,135 \mathrm{~kJ} / \mathrm{kg}}=$

3,86

2). Q2(debit air) $=0,000344 \mathrm{~m}^{3} /$ detik

$\mathrm{T} 1=15,2{ }^{\circ} \mathrm{C} \rightarrow h g 1=259,024 \mathrm{~kJ} / \mathrm{kg}$

$\mathrm{T} 2=67,6^{\circ} \mathrm{C} \rightarrow h g 2=292,092 \mathrm{~kJ} / \mathrm{kg}$

$\mathrm{T} 3=53,2{ }^{\circ} \mathrm{C} \rightarrow h l 3 \approx h l 4=128,732 \mathrm{~kJ} / \mathrm{kg}$

$C O P=\frac{259,024-128,732}{292,092-259,024}=3,94$

3). Q3(debit air) $=0,000578 \mathrm{~m}^{3} /$ detik

$\mathrm{T} 1=18,5^{\circ} \mathrm{C} \rightarrow h g 1=260,795 \mathrm{~kJ} / \mathrm{kg}$

$\mathrm{T} 2=68,5^{\circ} \mathrm{C} \rightarrow h g 2=292,377 \mathrm{~kJ} / \mathrm{kg}$

$\mathrm{T} 3=56,8^{\circ} \mathrm{C} \rightarrow h l 3 \approx h l 4=134,200 \mathrm{~kJ} / \mathrm{kg}$ 
$C O P=\frac{260,795-134,200}{292,377-260,795}=4,01$

Tabel 1. Hasil penelitian water chiller dengan katup ekspansi termostatik

\begin{tabular}{|c|c|c|c|c|c|c|c|c|c|c|}
\hline No & $\begin{array}{c}\text { Debit Air } \\
\left(\mathrm{m}^{3} / \mathrm{detik}\right)\end{array}$ & $\begin{array}{c}\mathrm{T} 1 \\
\left({ }^{\circ} \mathrm{C}\right)\end{array}$ & $\begin{array}{c}\mathrm{T} 2 \\
\left({ }^{\circ} \mathrm{C}\right)\end{array}$ & $\begin{array}{c}\mathrm{T} 3 \\
\left({ }^{\circ} \mathrm{C}\right)\end{array}$ & $\begin{array}{c}\mathrm{T} 4 \\
\left({ }^{\circ} \mathrm{C}\right)\end{array}$ & $\begin{array}{c}h g 1 \\
(\mathrm{~kJ} / \mathrm{kg})\end{array}$ & $\begin{array}{c}h g 2 \\
(\mathrm{~kJ} / \mathrm{kg})\end{array}$ & $\begin{array}{c}h l 3 \approx \\
h l 4 \\
(\mathrm{~kJ} / \mathrm{kg})\end{array}$ & $\begin{array}{c}\mathrm{T} \text { air } \\
\text { kelu } \\
\text { ar } \\
\left({ }^{\circ} \mathrm{C}\right)\end{array}$ & $\begin{array}{c}C O P: \\
\frac{h_{1}-h_{4}}{h_{2}-h_{1}}\end{array}$ \\
\hline 1. & 0,000109 & 14,0 & 66,0 & 52,0 & 8,0 & 258,370 & 292,505 & 126,590 & 10,0 & 3,86 \\
\hline 2. & 0,000344 & 15,2 & 67,6 & 53,2 & 10,2 & 259,024 & 292,092 & 128,732 & 15,0 & 3,95 \\
\hline 3. & 0,000578 & 18,5 & 68,5 & 56,8 & 13,0 & 260,795 & 292,377 & 134,200 & 19,0 & 4,01 \\
\hline
\end{tabular}

Data penelitian ketika Water Chiller beroperasi dengan menggunakan pipa kapiler :

1) $\mathrm{Q} 1$ (debit air) $=0,000109 \mathrm{~m}^{3} /$ detik

$\mathrm{T} 1=15^{\circ} \mathrm{C} \rightarrow h g 1=258,915 \mathrm{~kJ} / \mathrm{kg}$

$\mathrm{T} 2=69,5^{\circ} \mathrm{C} \rightarrow h g 2=292,999 \mathrm{~kJ} / \mathrm{kg}$

$\mathrm{T} 3=58,2^{\circ} \mathrm{C} \rightarrow h l 3 \approx h l 4=136,457 \mathrm{~kJ} / \mathrm{kg}$

$C O P=\frac{258,915-136,457}{292,999-258,915}=\frac{122,458 \mathrm{~kJ} / \mathrm{kg}}{34,084 \mathrm{~kJ} / \mathrm{kg}}=$

3,59

2). $\mathrm{Q} 2$ (debit air) $=0,000344 \mathrm{~m}^{3} /$ detik

$\mathrm{T} 1=18^{\circ} \mathrm{C} \rightarrow h g 1=260,530 \mathrm{~kJ} / \mathrm{kg}$
$\mathrm{T} 2=71,4^{\circ} \mathrm{C} \rightarrow h g 2=294,244 \mathrm{~kJ} / \mathrm{kg}$

$\mathrm{T} 3=58,9^{\circ} \mathrm{C} \rightarrow h l 3 \approx h l 4=136,935 \mathrm{~kJ} / \mathrm{kg}$ $C O P=\frac{260,530-136,935}{294,244-260,530}=\frac{123,595 \mathrm{~kJ} / \mathrm{kg}}{33,714 \mathrm{~kJ} / \mathrm{kg}}=$ 3,67

3). $\mathrm{Q} 3$ (debit air) $=0,000578 \mathrm{~m}^{3} /$ detik

$\mathrm{T} 1=21,3^{\circ} \mathrm{C} \rightarrow h g 1=262,272 \mathrm{~kJ} / \mathrm{kg}$

$\mathrm{T} 2=72,8^{\circ} \mathrm{C} \rightarrow h g 2=294,098 \mathrm{~kJ} / \mathrm{kg}$

$\mathrm{T} 3=62,4^{\circ} \mathrm{C} \rightarrow h l 3 \approx h l 4=143,325 \mathrm{~kJ} / \mathrm{kg}$

$C O P=\frac{262,272-143,325}{294,098-262,272}=\frac{118,947 \mathrm{~kJ} / \mathrm{kg}}{31,826 \mathrm{~kJ} / \mathrm{kg}}=$

3,74

Tabel 2. Hasil penelitian water chiller dengan pipa kapiler

\begin{tabular}{|c|c|c|c|c|c|c|c|c|c|c|}
\hline No & $\begin{array}{c}\text { Debit Air } \\
\left(\mathrm{m}^{3} / \mathrm{detik}\right)\end{array}$ & $\begin{array}{c}\mathrm{T} 1 \\
\left({ }^{\circ} \mathrm{C}\right)\end{array}$ & $\begin{array}{c}\mathrm{T} 2 \\
\left({ }^{\circ} \mathrm{C}\right)\end{array}$ & $\begin{array}{c}\mathrm{T} 3 \\
\left({ }^{\circ} \mathrm{C}\right)\end{array}$ & $\begin{array}{c}\mathrm{T} 4 \\
\left({ }^{\circ} \mathrm{C}\right)\end{array}$ & $\begin{array}{c}h g 1 \\
(\mathrm{~kJ} / \mathrm{kg})\end{array}$ & $\begin{array}{c}h g 2 \\
(\mathrm{~kJ} / \mathrm{kg})\end{array}$ & $\begin{array}{c}h l 3 \approx \\
h l 4 \\
(\mathrm{~kJ} / \mathrm{kg})\end{array}$ & $\begin{array}{c}\mathrm{T} \text { air } \\
\text { kelu } \\
\text { ar } \\
\left({ }^{\circ} \mathrm{C}\right)\end{array}$ & $\begin{array}{c}C O P: \\
\frac{h_{1}-h_{4}}{h_{2}-h_{1}}\end{array}$ \\
\hline 1. & 0,000109 & 15,0 & 69,5 & 58,2 & 10,0 & 258,915 & 292,999 & 136,457 & 12,0 & 3,59 \\
\hline 2. & 0,000344 & 18,0 & 71,4 & 58,9 & 12,5 & 260,530 & 294,244 & 136,935 & 18,0 & 3,67 \\
\hline 3. & 0,000578 & 21,3 & 72,8 & 62,4 & 15,5 & 262,272 & 294,098 & 143,325 & 23,0 & 3,74 \\
\hline
\end{tabular}

\subsection{Pembahasan}

Berdasarkan data penelitian yang didapat bahwa dengan melihat keadaan tersebut maka dapat dikatakan katup ekspansi termostatik memiliki kemampuan pendinginan yang lebih baik dibandingkan pipa kapiler. Hal ini disebabkan karena katup ekspansi termostatik dapat bekerja dengan cepat terhadap perubahan beban dan perubahan temperatur evaporator. Perubahan tersebut akan mengontrol bukaan katup sehingga laju aliran massa refrigeran cenderung disesuaikan dengan perubahan beban pendinginan. Dalam hal ini, laju aliran massa katup ekspansi termostatik juga lebih besar dari pipa kapiler, sehingga penyerapan kalor pada evaporator dan pelepasan kalor pada kondensor menjadi lebih besar. 


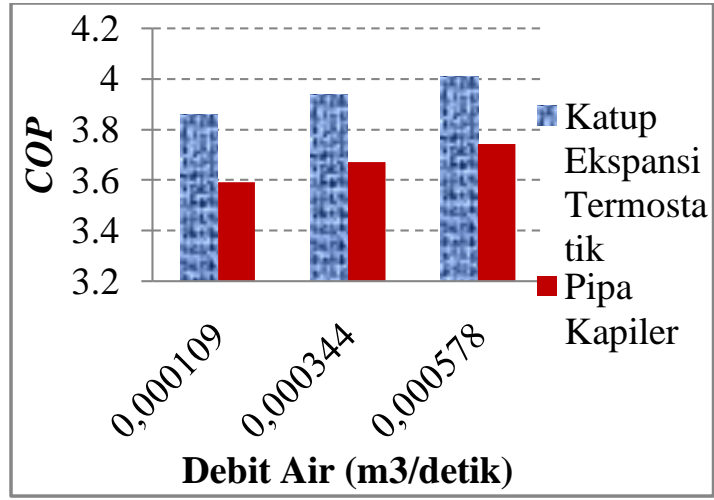

Gambar 7. Grafik perbandingan debit air terhadap nilai $C O P$ kedua alat ekspansi

Dari grafik di atas dapat kita lihat bahwa nilai $C O P$ dari katup ekspansi termostatik lebih besar dibandingkan dengan nilai $C O P$ dari pipa kapiler. Pada debit air sebesar $0,000578 \mathrm{~m}^{3} / \mathrm{s}$, katup ekspansi termostatik mempunyai nilai COP sebesar 4,01 sedangkan pipa kapiler mempunyai nilai $C O P$ sebesar 3,74.

Bertambahnya debit air menyebabkan energi yang diserap oleh refrigeran di evaporator menjadi bertambah besar, sedangkan kerja kompresor tidak mengalami perubahan yang begitu signifikan atau bahkan dapat dikatakan tetap.

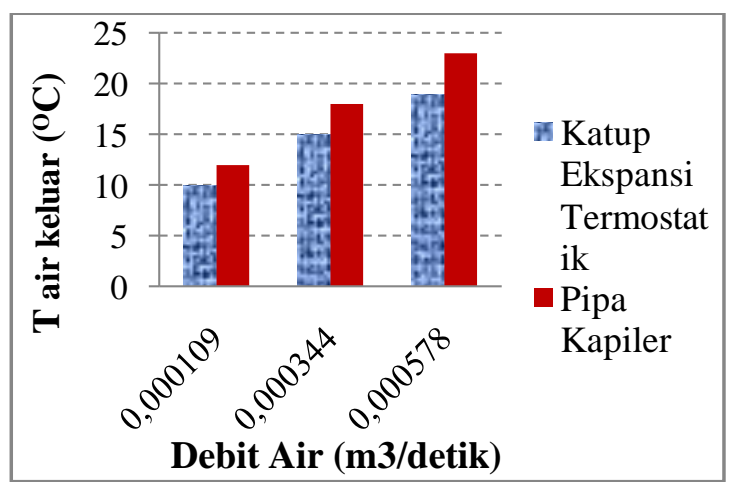

Gambar 8. Grafik pengaruh debit air pada temperatur air keluar water chiller

Dari gambar di atas dapat dilihat bahwa temperatur air keluar sistem dengan menggunakan katup ekspansi termostatik lebih rendah dibanding dengan menggunakan pipa kapiler. Ketika water chiller beroperasi dengan menggunakan katup ekspansi termostatik dan pada debit air $0,000109 \mathrm{~m}^{3} /$ detik, water chiller mampu mendinginkan air sampai dengan $10^{\circ} \mathrm{C}$, sedangkan ketika water chiller beroperasi menggunakan pipa kapiler mampu mendinginkan air sampai dengan $12^{\circ} \mathrm{C}$. Saat debit air $0,000578 \mathrm{~m}^{3} / \mathrm{s}$ katup ekspansi termostatik mampu mendinginkan sampai $19^{\circ} \mathrm{C}$ sedangkan pipa kapiler $23^{\circ} \mathrm{C}$. Kemampuan pendinginan water chiller di pengaruhi oleh nilai $C O P$ sistem tersebut, untuk nilai $C O P$ yang lebih besar berarti kemampuan pendinginan akan semakin besar pula. Pada percobaan ini katup ekspansi termostatik mempunyai nilai $C O P$ yang lebih besar dari pipa kapiler, dan efek pendinginan yang dihasilkan oleh katup ekspansi termostatik pun lebih baik dibandingkan pipa kapiler.

\section{Kesimpulan}

Dari penelitian yang dilakukan pada sistem pendingin York Water Chiller yang memiliki daya $2 \mathrm{PK}$, dapat ditarik kesimpulan sebagai berikut:

1. Katup ekspansi termostatik mempunyai nilai COP (Coefficient Of Performance) antara 3,86 hingga 4,01, sedangkan pipa kapiler mempunyai nilai $C O P$ (Coefficient Of Performance) antara 3,59 hingga 3,74.

2. Pada debit air sebesar 0,000109 $\mathrm{m}^{3} /$ detik katup ekspansi termostatik mampu menghasilkan temperatur air keluaran (chilled water) evaporator sebesar $10^{\circ} \mathrm{C}$, sedangkan pipa kapiler menghasilkan temperatur sebesar $12^{\circ} \mathrm{C}$. Dan pada debit air sebesar 0,000578 $\mathrm{m}^{3} /$ detik katup ekspansi termostatik mampu menghasilkan temperatur air keluaran (chilled water) evaporator sebesar $19^{\circ} \mathrm{C}$, sedangkan pipa kapiler menghasilkan temperatur sebesar $23^{\circ} \mathrm{C}$. Sehingga katup ekspansi termostatik ketika digunakan pada sistem pendingin water chiller mempunyai performansi dan efek pendinginan yang lebih baik dibandingkan dengan pipa kapiler. 


\section{Ucapan Terima Kasih}

Terima kasih ditujukan kepada PT. Total E\&P Indonesia Balikpapan yang telah memberikan tempat dan fasilitas dalam penelitian ini.

\section{Daftar Pustaka}

Ashrae, 2000, HVAC Systems and Equipment Handbook, Bandung.

Dossat, Roy. J, 1984, Principles of Refrigeration, John Wiley \& Sons Inc, New York.

Hasan, Syamsuri dkk, 2008, Refrigerasi Dan Tata Udara, Departemen Pendidikan Nasional, Jakarta.

Jamil, Asep Ahmad, 2012, Pembuatan Mesin Pendingin, FMIPA, Depok.

Moran, J,H.N. Shapiro, 2006, Fundamentals of Engineering Thermodynamics $5^{\text {th }}$ Edition, John Wiley \& Sons Inc, New York.
Suarnadwipa, Nengah \& Astawa, Ketut, 2009, Pengujian Model Water Chiller Sistem dengan Hidrokarbon sebagai Refrigeran Primer, Jurnal Ilmiah Teknik Mesin, Universitas Udayana, Bali.

Yudha, Mochamad R.A, 2013, Pengaruh Variasi Beban Pendingin Terhadap Prestasi Kerja Mesin Pendingin, FTUJ, Jember.

http://www.akucintasejarah.wordpress .com/, 12 Juni 2014, Mesin Pendingin Ditemukan

http://www.beritaiptek.com/, 12 Juni 2014, Siklus Refrigerasi Kompresi Uap.

http://www.wikipedia.com/, 20 April 2014, mesin pendingin water chiller. 